\title{
Sprawozdanie z przebiegu V edycji Wolnej Szkoły Nauk Filozoficznych i Społecznych im. Profesora Jana Szczepańskiego
}

Piąta edycja Wolnej Szkoły Nauk Filozoficznych i Społecznych im. Profesora Jana Szczepańskiego odbyła się w dniach 8-11 października 2018 r. w Cieszynie, Ustroniu i Czeskim Cieszynie. Organizatorami wydarzenia były następujące podmioty i organizacje: Powiat Cieszyński, Miasto Cieszyn, Miasto Ustroń, Wydział Etnologii i Nauk o Edukacji Uniwersytetu Śląskiego w Katowicach, Wydział Ekonomiczno-Socjologiczny Uniwersytetu Łódzkiego, Centrum Pedagogiczne dla Polskiego Szkolnictwa Narodowościowego w Czeskim Cieszynie, Stowarzyszenie Samorządowe Ziemi Cieszyńskiej oraz Stowarzyszenie Wspierania Edukacji Międzykulturowej.

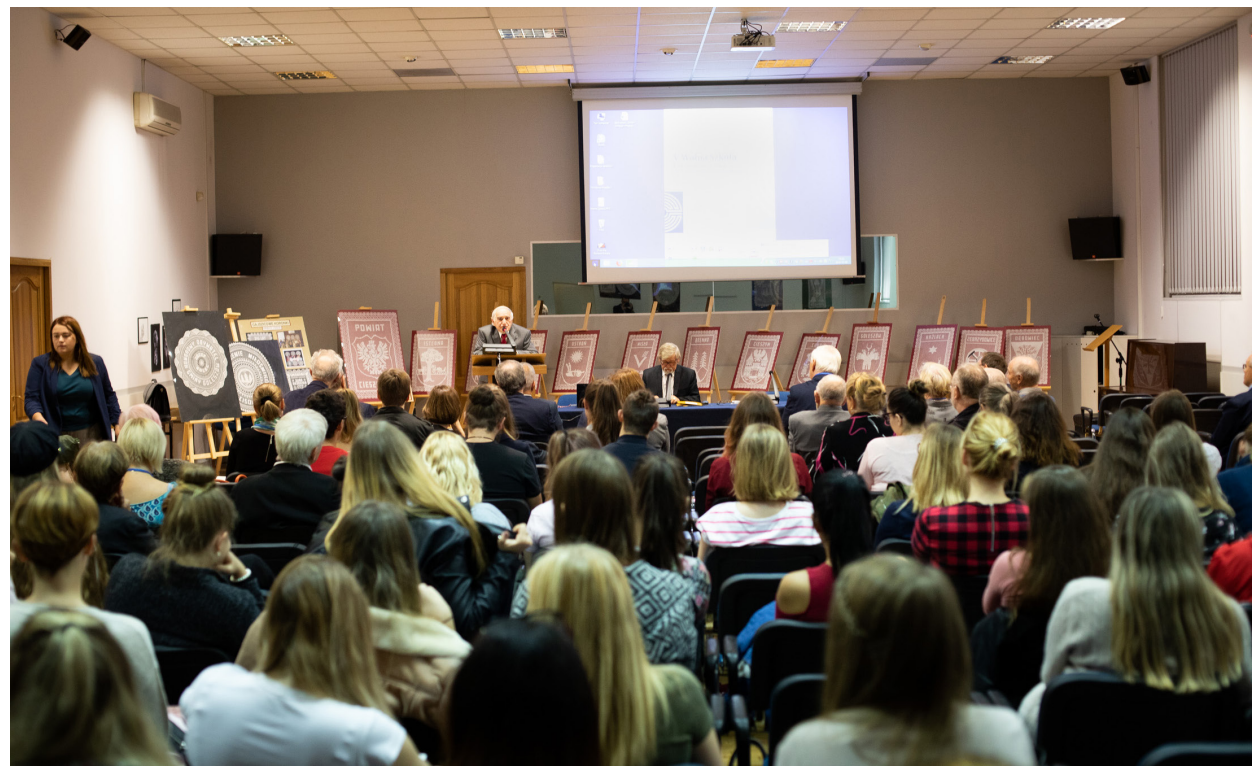

Wystąpienie prof. zw. dr. hab. Daniela Kadłubca podczas uroczystego otwarcia V edycji WSNFiS 
Patronatem Honorowym piątą edycję WSNFiS objęli Artur Szczepański, Jerzy Buzek - poseł do Parlamentu Europejskiego, Jan Olbrycht - poseł do Parlamentu Europejskiego, Janusz Król - starosta Powiatu Cieszyńskiego, Ryszard Macura - burmistrz Miasta Cieszyna, Ireneusz Szarzec - burmistrz Miasta Ustroń, prof. dr hab. Andrzej Kowalczyk - JM Rektor Uniwersytetu Śląskiego w Katowicach, prof. dr hab. Antoni Różalski - JM Rektor Uniwersytetu Łódzkiego oraz dr hab. Dorota Misiejuk - przewodnicząca Stowarzyszenia Wspierania Edukacji Międzykulturowej.

W roku 2018 uroczysta inauguracja Wolnej Szkoły Nauk Filozoficznych i Społecznych odbyła się w cieszyńskim Wydziale Etnologii i Nauk o Edukacji Uniwersytetu Śląskiego w Katowicach, gdzie przybyłych gości powitali dr hab. Marek Rembierz oraz mgr Stanisław Kubicius - radny Powiatu Cieszyńskiego. Następnie głos zabrali przedstawiciele organizatorów WSNFiS w osobach prof. zw. dr. hab. Daniela Kadłubca - Honorowego Rektora WSNFiS, Ireneusza Szarzca - burmistrza Miasta Ustroń, Ryszarda Macury - burmistrza Miasta Cieszyna, prof. dr. hab. Pawła Starosty - prorektora ds. Współpracy Krajowej i Międzynarodowej (Uniwersytet Łódzki), prof. zw. dr. hab. Zenona Gajdzicy - dziekana Wydziału Etnologii i Nauk o Edukacji Uniwersytetu Śląskiego w Katowicach oraz dr. hab. Andrzeja Kasperka - prodziekana ds. Naukowych i Współpracy z Zagranicą (WEiNoE UŚ).



Spotkanie podczas V edycji WSNFiS; od lewej: burmistrz Ustronia Ireneusz Szarzec, prof. zw. dr hab. Daniel Kadłubiec, prof. zw. dr hab. Jerzy Bartmiński 
Po zakończeniu wystąpień okolicznościowych przyszedł czas na prezentację publikacji książkowych powiązanych z projektem Wolnej Szkoły Nauk Filozoficznych i Społecznych, której dokonał dr hab. Marek Rembierz. Pierwszą z nich był czwarty tom książki pt. W kręgu myśli Profesora Jana Szczepańskiego, stanowiącej zbiór materiałów dokumentujących przebieg konferencji zorganizowanej w ramach WSNFiS w ubiegłym roku. Natomiast druga publikacja, zatytułowana Spotkania filozoficzno-socjologiczne na pograniczu w ramach Polsko-Czeskiej Wolnej Szkoły Nauk Filozoficznych i Społecznych im. Profesora Jana Szczepańskiego, powstała w ramach projektu realizowanego na Wydziale Etnologii i Nauk o Edukacji. Podczas inauguracji tegorocznej edycji WSNFiS zgromadzeni goście mieli także okazję obejrzeć wystawę wybranych koronek Józefa Golca.

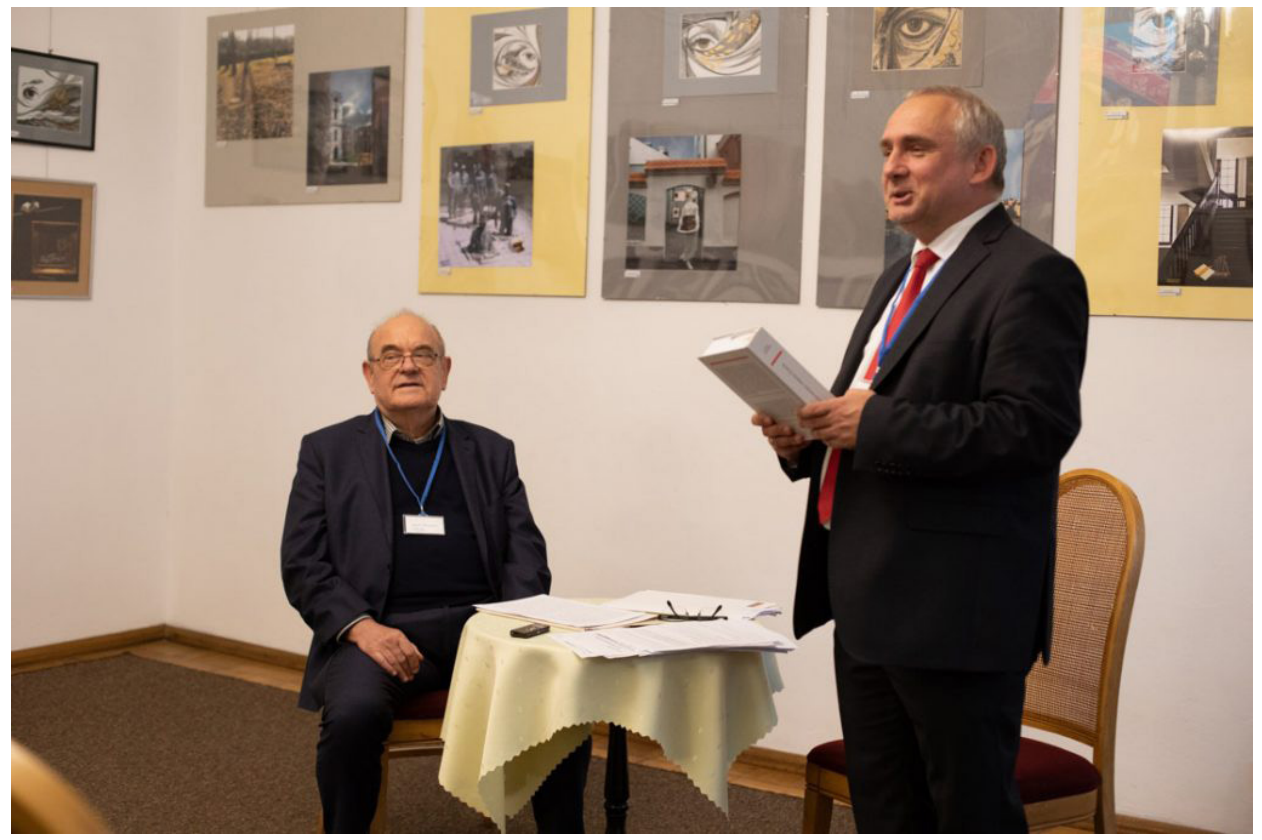

Podczas promocji najnowszej książki ks. prof. Janusza Mariańskiego: od lewej ks. prof. zw. dr hab. Janusz Mariański, dr hab. Marek Rembierz

W ramach piątej edycji Wolnej Szkoły Nauk Filozoficznych i Społecznych z wykładem inauguracyjnym zatytułowanym Polski etos narodowy: szlachecki, chłopski, miejski...? wystąpił prof. zw. dr hab. Jerzy Bartmiński. W następnej kolejności odbyły się wystąpienia z cyklu Wykłady Mistrzów, które w tym roku poprowadzili prof. zw. dr hab. Bogdan Dembiński z wykładem pt. Od jaskini Platona do fizyki kwantowej oraz prof. dr hab. Krzysztof Wielecki, który przedstawił Istotę różnicy między kultura regionalną 
i masowa. Wystąpieniom prelegentów towarzyszyła wspólna dyskusja nad poruszanymi w wykładach zagadnieniami. Oficjalną część inauguracyjną tegorocznej WSNFiS zakończył przejazd uczestników konferencji do Ustronia, gdzie, wzorem lat ubiegłych, złożyli kwiaty pod pomnikiem jej patrona - Profesora Jana Szczepańskiego.

Po przerwie obiadowej w MDK „Prażakówka” w Ustroniu rozpoczęły się obrady pierwszego dnia konferencji, w których głos zabrali: prof. zw. dr hab. Danuta Walczak-Duraj - Humanizacja technologii czy dehumanizacja badań socjologicznych? Wiodace wyzwania dla socjologów $w$ dobie cywilizacji algorytmów, prof. dr hab. Wiesław Wójcik - Paradoksy nauczania uniwersyteckiego i badań naukowych $w$ teorii i praktyce oraz prof. dr hab. Wiesław Gumuła - Społeczny kontekst finansów i gospodarki. Ostatnim punktem programu pierwszego dnia konferencji była promocja książki ks. prof. Janusza Mariańskiego zatytułowanej Kondycja religijna i moralna młodzieży szkół średnich $w$ latach 1988-1998-2005-2017 (raport z ogólnopolskich badań socjologicznych), która odbyła się w Muzeum Ustrońskim. Spotkanie moderował dr hab. Marek Rembierz z Wydziału Etnologii i Nauk o Edukacji UŚ, a na temat twórczości ks. prof. zw. dr. hab. Janusza Mariańskiego wypowiedzieli się: prof. zw. dr hab. Danuta Walczak-Duraj, prof. zw. dr hab. Wojciech Świątkiewicz, prof. dr hab. Ewa Ogrodzka-Mazur, prof. dr hab. Urszula Swadźba, prof. dr hab. Elżbieta Firlit, prof. dr hab. Paweł Starosta, prof. dr hab. Krzysztof Wielecki, prof. dr hab. Wiesław Wójcik oraz dr hab. Andrzej Kasperek. Na zakończenie pierwszego dnia konferencji uczestnicy spędzili wspólnie czas przy uroczystej kolacji w ustrońskim hotelu Wilga.

Pierwsza część obrad drugiego dnia konferencji odbyła się w hotelu Wilga, gdzie z referatami wystąpiły prof. dr hab. Kaja Kazimierska - Biografia i doświadczenie pokoleniowe, dr Katarzyna Waniek - Zagraniczne wyjazdy edukacyjne jako forma emancypacji, dr Iza Desperak - Kobieca specyfika kultury Śląska Cieszyńskiego, dr inż. Barbara Szczepańska - Rytuały pogrzebowe w pamięci mieszkańców obszarów wiejskich Dolnego Śląska oraz dr Maria Pleskaczyńska - Wewnętrzność, nadzieja i beznadzieja. Konflikt i bliskość myśli Jana Szczepańskiego i Henryka Elzenberga. Wzorem lat ubiegłych nieodłączną część drugiego dnia konferencji stanowiły dwugodzinne warsztaty metodologiczne przeprowadzone przez prof. dr hab. Kaję Kazimierską oraz dr Katarzynę Waniek z Uniwersytetu Łódzkiego. Pobyt w Ustroniu zakończył się wspólnym obiadem.

W godzinach popołudniowych uczestnicy udali się autokarem do Polskiego Gimnazjum im. Juliusza Słowackiego w Czeskim Cieszynie, gdzie odbyła się trzecia i ostatnia część konferencji zorganizowanej w ramach tegorocznej edycji WSNFiS poprzedzona 
specjalnie przygotowanym na tę okazję występem chóru Polskiego Towarzystwa Artystycznego ARS MUSICA „Collegium Iuvenum” pod dyrekcją dr. Leszka Kaliny. W auli Polskiego Gimnazjum z wykładami wystąpili ks. prof. zw. dr hab. Janusz Mariański - Wartości codzienne i podstawowe $w$ świadomości młodzieży maturalnej $w$ Puławach oraz prof. zw. dr hab. Tadeusz Sławek - Między rozumem szlachetnym a furią. O człowieku zranionym. W następnej kolejności swoje referaty wygłosiły także mgr Iwona Majchrzak - Działalność Jana Szczepańskiego w Komitecie Badań i Prognoz „Polska 2000” PAN w latach 1969-1984 oraz mgr Katarzyna Szkaradnik - Jana Wantuły eksplorowanie obrzeży archiwum. Po obradach zakończonych dyskusją uczestnicy konferencji wrócili do Cieszyna oraz Ustronia.

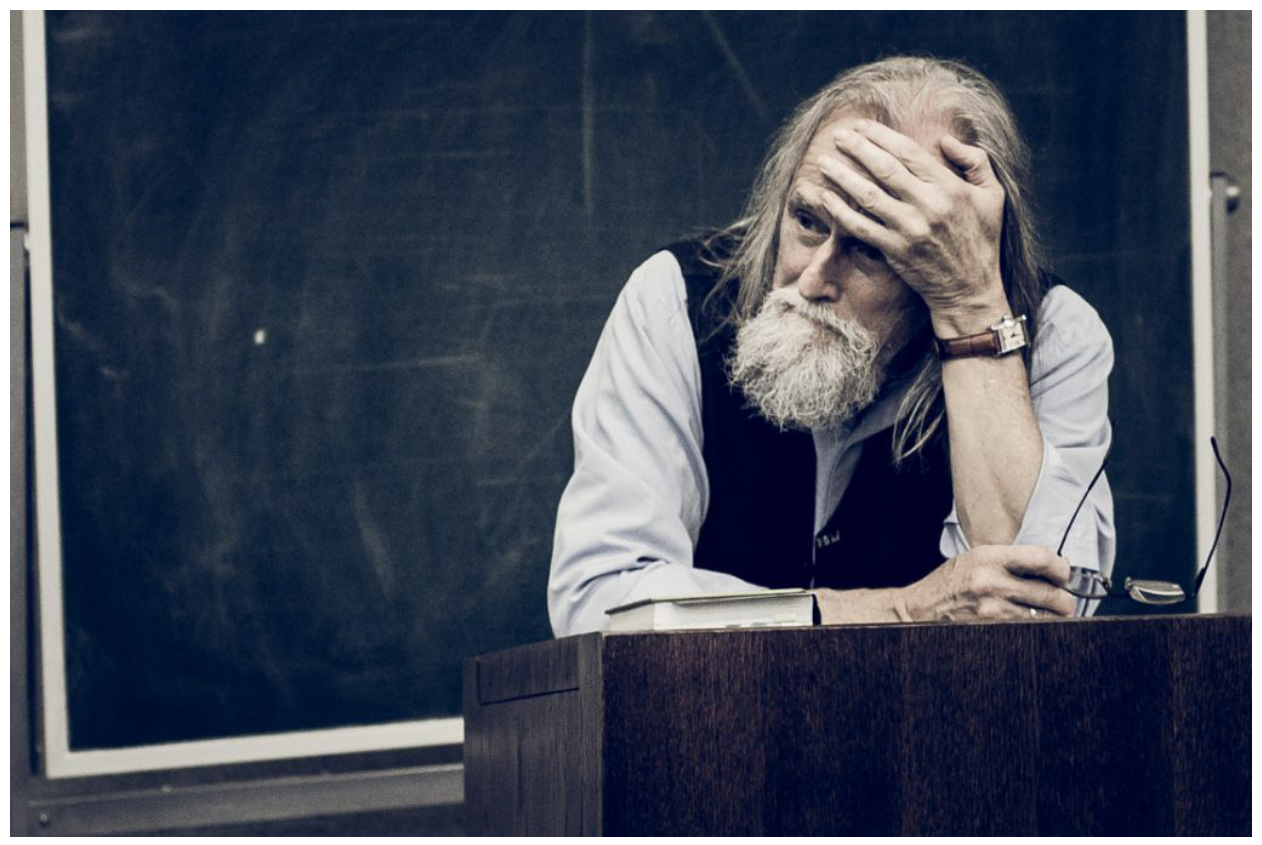

Prof. zw. dr hab. Tadeusz Sławek podczas wykładu wygłoszonego w Polskim Gimnazjum im. J. Słowackiego w Czeskim Cieszynie

Podobnie jak w poprzednich latach, dwa ostatnie dni Wolnej Szkoły Nauk Filozoficznych i Społecznych były przeznaczone na spotkania oraz zajęcia z cieszyńską i ustrońską młodzieżą. W V edycji WSNFiS wzięli udział uczniowie ogólnokształcących i zawodowych szkół średnich, oddziałów gimnazjalnych, a także dwóch ostatnich klas szkoły podstawowej. Otwarcie WSNFiS dla młodzieży nastąpiło w Centrum Konferencyjnym UŚ WEiNOE, gdzie po powitaniu przybyłych z cieszyńskich szkół gości odbył się panel 
dyskusyjny na temat Kultura regionalna $w$ życiu młodego pokolenia - balast przeszłości czy kapitał na przyszłość, który poprowadzili dr hab. Bogusław Dziadzia z Wydziału Etnologii i Nauk o Edukacji UŚ oraz mgr Stanisław Kubicius. W roli ekspertów w debacie wystąpili znawcy i popularyzatorzy kultury regionalnej: prof. zw. dr hab. Daniel Kadłubiec, Danuta Koenig, Małgorzata Kiereś oraz Ewa Błasiak-Kanafek. Po przerwie obiadowej, dla najmłodszych uczestników WSNFiS został przeprowadzony szereg warsztatów. Dla młodzieży ze szkół średnich zajęcia przygotowali pracownicy Wydziału Etnologii i Nauk o Edukacji UŚ, którzy poprowadzili warsztaty fotograficzne Patrzeć $i$ widzieć - zatrzymać obraz otaczającego świata $w$ fotografii (mgr inż. Leszek Żaba) oraz warsztaty teatralne Poznaj samego siebie (dr Ewa Tomaszewska). Propozycje WSNFiS dla młodszych uczniów obejmowały z kolei warsztaty Na lekcji w wiślańskiej szkole, przygotowane przez dr. Michała Kawuloka z Muzeum Beskidzkiego im. Andrzeja Podżorskiego w Wiśle oraz Język migowy jako forma komunikacji integrująca społeczeństwo, które przeprowadziły studentki kierunku pedagogika osób niepełnosprawnych z arteterapią z Wydziału Etnologii i Nauk o Edukacji UŚ: lic. Paulina Woźnica, lic. Katarzyna Rakus i lic. Justyna Piasecka.

Jak co roku otwarcie dnia WSNFiS dla młodzieży ze szkół ustrońskich odbyło się w auli Gimnazjum nr 1 im. Jana Szczepańskiego, gdzie zebranych gości powitał dyrektor szkoły mgr Leszek Szczypka. Następnie, wzorem lat ubiegłych, zgromadzona młodzież wysłuchała wykładu inauguracyjnego Honorowego Rektora WSNFiS prof. zw. dr. hab. Daniela Kadłubca, który w tym roku nosił tytuł Rozważania Profesora Jana Szczepańskiego o znaczeniu dziedzictwa kulturowego. Po zakończeniu części inauguracyjnej uczestnicy mieli okazję wziąć udział w przygotowanych specjalnie dla nich zajęciach. Podobnie jak w Cieszynie dla młodzieży ze szkół średnich przeprowadzili je pracownicy Wydziału Etnologii i Nauk o Edukacji UŚ: warsztaty fotograficzne Patrzeć i widzieć - zatrzymać obraz otaczającego świata $w$ fotografii (mgr inż. Leszek Żaba) oraz warsztaty teatralne Poznaj samego siebie (dr Ewa Tomaszewska). Natomiast dla młodszych uczniów przewidziano zajęcia Na lekcji w wiślańskiej szkole (dr Michał Kawulok, Muzeum Beskidzkie im. Andrzeja Podżorskiego w Wiśle) oraz warsztaty z zakresu psychodramy przygotowane przez dr Dorotę Prysak z cieszyńskiego Wydziału Etnologii i Nauk o Edukacji UŚ.

Zgodnie z tradycją V edycja Wolnej Szkoły Nauk Filozoficznych i Społecznych im. Profesora Jana Szczepańskiego zakończyła się wspólnym obiadem w stołówce ustrońskiej Szkoły Podstawowej nr 1. 